\title{
Predicting Fontan failure: Why a chylothorax matters
}

\author{
Travis J. Wilder, MD
}

From the Department of Cardiothoracic Surgery, University of Utah, Salt Lake City, Utah.

Disclosures: Author has nothing to disclose with regard to commercial support.

Received for publication Jan 22, 2018; accepted for publication Jan 30, 2018; available ahead of print March 9, 2018.

Address for reprints: Travis J. Wilder, MD, Division of Cardiothoracic Surgery, University of Utah, 30 North 1900

East, No. 3C127 SOM, Salt Lake City, UT 84132 (E-mail: travis.wilder@hsc.utah.edu).

J Thorac Cardiovasc Surg 2018;155:2078-9

$0022-5223 / \$ 36.00$

Copyright $(2) 2018$ by The American Association for Thoracic Surgery

https://doi.org/10.1016/j.jtcvs.2018.01.044

It is remarkable to consider the advances that have been made in single-ventricle palliation during the past 60 years. What was once for most a death sentence in early childhood is now a chronic condition allowing survival into the fifth decade of life. Improved outcomes for singe-ventricle defects would not have been possible, at least in part, without the Fontan-Kreutzer (Fontan) operation. ${ }^{2,3}$ The Fontan operation completes the final stage of single-ventricle palliation by bypassing the subpulmonary ventricle and placing the pulmonary and systemic blood flow in series, resulting in passive systemic venous return to the pulmonary arteries. $^{2-4}$

Despite the improved outcomes for patients after singleventricle palliation, ultimately all patients have Fontan failure occur. The mechanism of single-ventricle failure has been widely investigated, and clinicians have attempted to identify characteristics that may predispose patients toward early Fontan failure. The ability to recognize which patients are most susceptible to failure of the Fontan circulation, however, remains incomplete. ${ }^{5}$

The study by Lo Rito and colleagues ${ }^{6}$ in the current issue of The Journal of Thoracic and Cardiovascular Surgery demonstrates that patients who have a chylothorax develop soon after the Fontan operation may be

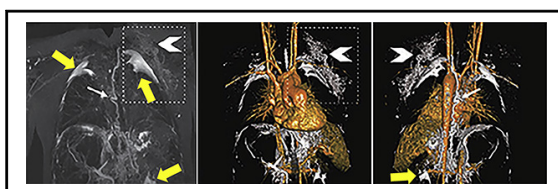

MRI showing abnormal lymphatic drainage associated with Fontan circulation.

\section{Central Message}

Children in whom post-Fontan chylothorax develops may be less tolerant of single-ventricle physiology. Predicting who is at risk for chylothorax may improve outcomes after singleventricle palliation.

See Article page 2069.

less tolerant of single-ventricle palliation. These patients were more susceptible to Fontan-related complications, and ultimately single-ventricle palliation failed earlier for them than for patients without a chylothorax. Importantly, the study showed a worse 10-year survival for patients who had an early post-Fontan chylothorax develop, along with an increased risk of composite adverse events including, death, transplantation, Fontan takedown, protein losing enteropathy, and plastic bronchitis. The findings by Lo Rito and colleagues ${ }^{6}$ are consistent with previous studies that have identified a relationship between early chylothorax after Fontan and an increased incidence of protein losing enteropathy and plastic bronchitis $^{7,8}$; an association thought to be attributable to the increased lymphatic pressure secondary to the Fontan circulation (Figure 1). Possible clinical implications include evidence to support closer surveillance and
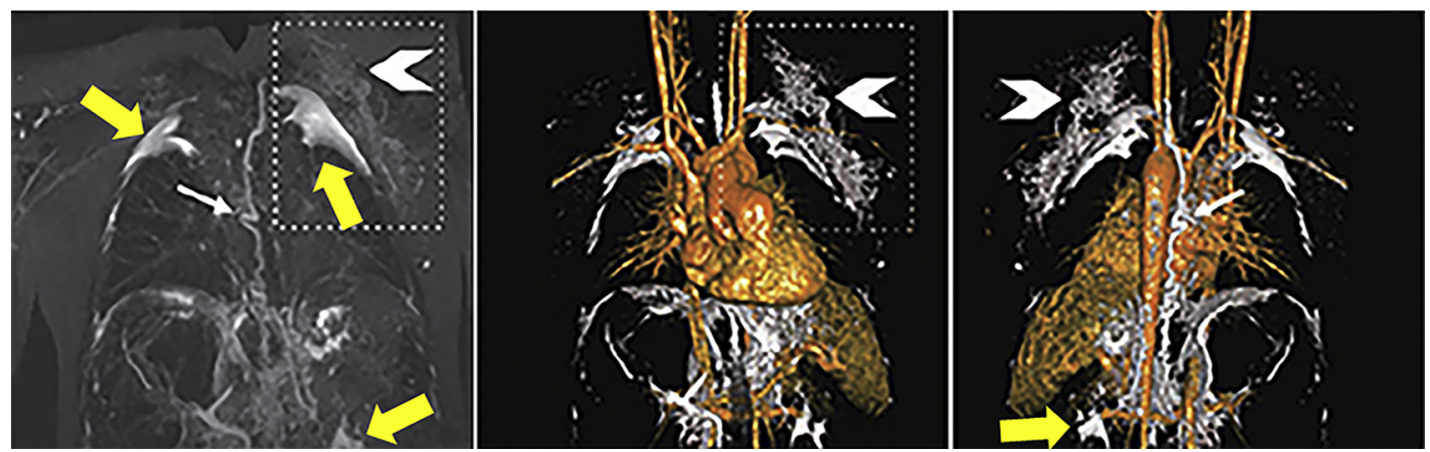

FIGURE 1. Magnetic resonance images showing abnormal lymphatic collaterals with associated increased tissue edema and "pools" of fluid accumulation (dashed box), presumably related to abnormal lymphatic overload. White arrows, abnormal tortuous thoracic duct; white arrow heads, abnormal lymphatic collaterals; yellow arrows, areas of increased tissue edema. Reprinted with permission from the American Journal of Roentgenology. ${ }^{1}$ 
consideration of early intervention (Fontan takedown or transplantation) for patients who have a post-Fontan chylothorax develop.

As Lo Rito and colleagues ${ }^{6}$ mention, no pre-Fontan characteristics were associated with development of an acute chylothorax after the Fontan operation. In addition, the retrospective nature of the study only allows speculation as to why early chylothorax predisposes patients toward Fontan failure. Nonetheless, given the strong association between post-Fontan chylothorax and poor outcomes, future work should build on the study of Lo Rito and colleagues ${ }^{6}$ and seek to identify patient characterizes predictive of development of an early chylothorax.

Despite improved survival and better quality of life for patients with a functional single-ventricle circulation, Fontan palliation remains just that, a palliation strategy. To maintain the momentum of the past 60 years and continue to improve survival for patients with a functional singleventricle physiology, it is critical to identify patients who are less tolerant of the long-term effects of the Fontan circulation. This knowledge may help to develop screening programs and perhaps alternative management strategies for high-risk patients. No doubt, the article of Lo Rito and colleagues $^{6}$ will help improve care for patients with complex congenital heart defects.

\section{References}

1. Dori Y, Keller MS, Fogel MA, Rome JJ, Whitehead KK, Harris MA, et al. MRI of lymphatic abnormalities after functional single-ventricle palliation surgery. AJR Am J Roentgenol. 2014;203:426-31.

2. Fontan F, Baudet E. Surgical repair of tricuspid atresia. Thorax. 1971;26 240-8

3. Kreutzer G, Galíndez E, Bono H, De Palma C, Laura JP. An operation for the correction of tricuspid atresia. J Thorac Cardiovasc Surg. 1973;66:613-21.

4. Khairy P, Fernandes SM, Mayer JE Jr, Triedman JK, Walsh EP, Lock JE, et al Long-term survival, modes of death, and predictors of mortality in patients with Fontan surgery. Circulation. 2008;117:85-92.

5. Gewillig M. The Fontan circulation. Heart. 2005;91:839-46.

6. Lo Rito M, Al-Radi OO, Saedi A, Kotani Y, Sivarajan VB, Russell JL, et al. Chylothorax and pleural effusion in contemporary extracardiac fenestrated Fontan completion. J Thorac Cardiovasc Surg. 2018;155:2069-77.

7. Schumacher KR, Singh TP, Kuebler J, Aprile K, O'Brien M, Blume ED. Risk factors and outcome of Fontan-associated plastic bronchitis: a case-control study. J Am Heart Assoc. 2014;3:e000865.

8. Schumacher KR, Stringer KA, Donohue JE, Yu S, Shaver A, Caruthers RL, et al Fontan-associated protein-losing enteropathy and plastic bronchitis. J Pediatr. 2015;166:970-7. 